\title{
The ERS fellowship portfolio: fostering excellence and diversity
}

\author{
Rory E. Morty ${ }^{1}$, Louise E. Donnelly ${ }^{2}$, Daiana Stolz ${ }^{3}$, Nicolas Roche ${ }^{4}$, \\ Tobias Welte $^{5}$, Kathryn A. Forrest ${ }^{6}$, Christopher E. Brightling ${ }^{7}$ and \\ Guy G. Brusselle 8,9
}

Affiliations: ${ }^{1}$ Dept of Lung Development and Remodelling, Max Planck Institute for Heart and Lung Research, Bad Nauheim, Germany. ${ }^{2}$ Faculty of Medicine, National Heart and Lung Institute, Imperial College London, London, UK. ${ }^{3}$ Pulmonary Care Division, Internal Medicine, University Hospital Basel, Basel, Switzerland. ${ }^{4}$ Hopital Cochin, University Paris Descartes, Paris, France. ${ }^{5}$ Respiratory Medicine, Medical School Hannover, Hannover, Germany. 'Scientific Activities Dept, European Respiratory Society, Lausanne, Switzerland. ${ }^{7}$ Leicester NIHR Biomedical Research Centre, University of Leicester, Leicester, UK. ${ }^{8}$ Depts of Epidemiology and Respiratory Medicine, Erasmus Medical Center, Rotterdam, The Netherlands. ${ }^{9}$ Dept of Respiratory Medicine, Ghent University Hospital, Ghent, Belgium.

Correspondence: Rory E. Morty, Dept of Lung Development and Remodelling, Max Planck Institute for Heart and Lung Research, Parkstr. 1, 61231 Bad Nauheim, Germany. E-mail: rory.mortylampi-bn.mpg.de

@ERSpublications

The ERS fellowship portfolio continues to be refined, to respond to the changing needs of our Society. Under the 2016-2019 Fellowship strategy, a wide range of programmes is available, reflecting the diversity and global dimension of the ERS membership. http://bit.ly/2YEpOnv

Cite this article as: Morty RE, Donnelly LE, Stolz D, et al. The ERS fellowship portfolio: fostering excellence and diversity. Eur Respir J 2019; 54: 1901503 [https://doi.org/10.1183/13993003.01503-2019].

\section{Introduction}

The European Respiratory Society (ERS) has offered fellowships since 1997, and to date, more than 770 researchers have been recipients of ERS fellowships. Under the remit of the 2016-2019 ERS Fellowships and Awards Director, Rory E. Morty, the fellowship portfolio has been further developed and consolidated in order to meet the diverse needs of an increasingly global ERS membership and to help address unmet needs in respiratory research, in line with the Society's mission to promote lung health and to actively involve ERS members in the earlier phases of their career.

\section{A consolidated and diverse fellowship portfolio}

The current ERS fellowship portfolio builds on six diverse but complementary fellowship programmes, listed in table 1 . Trans-national mobility continues to be a key component in all fellowships offered by the ERS, enabling the training and career development of the next generation of respiratory researchers and clinicians.

The ERS fellowship portfolio continues to offer two well-established and complementary programmes: the Long-term Research Fellowship (LTRF) and Short-term Research Fellowship (STRF) programmes. Within these two schemes, collaborations with national or regional respiratory societies, and other scientific organisations, have been further developed (listed in table 1), which allows for co-funding of fellowships by the ERS together with national or regional respiratory societies or scientific organisations. The Clinical Training Fellowship (CTF) programme, introduced in 2015, is now a recognised element within the broader fellowship portfolio, and targets clinicians and qualified allied health professionals. Fellowship recipients can learn a specific skill or procedure at the host centre, with the ultimate objective to transfer 
TABLE 1 Current ERS fellowship portfolio as of June 2019

\begin{tabular}{|c|c|c|c|}
\hline Programme & Specific scheme(s) & Call deadline(s) and duration & $\begin{array}{l}\text { Estimated success } \\
\text { rate }^{\#}\end{array}$ \\
\hline $\begin{array}{l}\text { Short-term Research Fellowship (STRF) } \\
\text { Lead ERS person: Fellowships and } \\
\text { Awards Director (ERS Science Council) }\end{array}$ & $\begin{array}{l}\text { - Standard } \\
\text { - International } \\
\text { - Scientifically developing countries } \\
\text { - Walther Guerrero Ciquero (TB) } \\
\text { - In memory of Dr Valia Kechagia } \\
\text { - Jointly funded with the European Molecular Biology } \\
\text { - Jointly funded with the Indian Chest Society (ICS) } \\
\text { - Jointly funded with the Turkish Thoracic Society (TTS) } \\
\text { - Emiel F.M. Wouters STRF programme }\end{array}$ & $\begin{array}{l}\text { Deadline(s): } 1 \text { April and } 1 \text { October } \\
\text { every year } \\
\text { Fellowship duration: } 1-3 \text { months }\end{array}$ & $20-30 \%$ \\
\hline $\begin{array}{l}\text { Long-term Research Fellowship (LTRF) } \\
\text { Lead ERS person: Fellowships and } \\
\text { Awards Director (ERS Science Council) }\end{array}$ & $\begin{array}{l}\text { - Standard } \\
\text { - International } \\
\text { - Scientifically developing countries } \\
\text { - } \text { Child lung health (paediatrics) } \\
\text { - Jointly funded with European Molecular Biology } \\
\text { Organization (EMBO) } \\
\text { - Jointly funded with the Asociación Latinoamericana de } \\
\text { Tórax (ALAT) } \\
\text { - Jointly funded with the German Center for Lung } \\
\text { Research (Deutsches Zentrum für Lungenforschung; } \\
\text { DZL) } \\
\text { - Jointly funded with the Sociedad Española de } \\
\text { - Jeumología y Cirugía Torácica (SEPAR) } \\
\text { Langue Française (SPLF) }\end{array}$ & $\begin{array}{l}\text { Deadline: Mid-January each year } \\
\text { (please consult website for exact } \\
\text { dates) } \\
\text { Fellowship duration: } 6-12 \text { months, } \\
\text { except for DZL centres in } \\
\text { Germany ( } 24 \text { months) }\end{array}$ & $20-25 \%$ \\
\hline $\begin{array}{l}\text { Clinical Training Fellowship (CTF) } \\
\text { Lead ERS person: Education Council } \\
\text { Chair (ERS Education Council) }\end{array}$ & $\begin{array}{l}\text { - Standard } \\
\text { - International } \\
\text { - Scientifically developing countries } \\
\text { - Jointly funded with the Indian Chest Society (ICS) }\end{array}$ & $\begin{array}{l}\text { Deadline(s): } 1 \text { April and } 1 \text { October } \\
\text { every year } \\
\text { Fellowship duration: } 1-6 \text { months }\end{array}$ & $20-25 \%$ \\
\hline $\begin{array}{l}\text { RESPIRE Marie Skłodowska-Curie } \\
\text { Fellowship } \\
\text { Lead ERS person: Fellowships and } \\
\text { Awards Director (ERS Science Council) }\end{array}$ & $\begin{array}{l}\text { - 24-month European fellowships } \\
\text { - } 36 \text {-month global fellowships } \\
\text { This programme receives co-funding from the EU } \\
\text { Horizon } 2020 \text { research and innovation programme under } \\
\text { the Marie Sklodowska-Curie grant agreements number } \\
847462\end{array}$ & $\begin{array}{l}\text { Deadline(s): } 1 \text { May during } 2020- \\
\text { 2021-2022 (three calls based on } \\
\text { grant agreement with EU) } \\
\text { Fellowship duration: } 24 \text { or } \\
36 \text { months }\end{array}$ & Less than $15 \%$ \\
\hline $\begin{array}{l}\text { Guideline Methodology Fellowship } \\
\text { Lead ERS person: Guidelines Director } \\
\text { (ERS Science Council) }\end{array}$ & $\begin{array}{l}\text { This programme encompasses two parts: } \\
\text { - The first is dedicated to training in systematic reviews } \\
\text { and is hosted by Cochrane Iberoamerica in } \\
\text { Barcelona, Spain } \\
\text { - The second focuses on developing guidelines and is } \\
\text { hosted by National Institute for Health and Care } \\
\text { Excellence (NICE) in Manchester, UK }\end{array}$ & $\begin{array}{l}\text { Deadline: June every year (please } \\
\text { consult website for exact dates) } \\
\text { Fellowship duration: } 6 \text { months }\end{array}$ & Less than $15 \%$ \\
\hline $\begin{array}{l}\text { Joint Public Health Fellowship } \\
\text { Lead ERS person: Fellowships and } \\
\text { Awards Director (ERS Science Council) } \\
\text { in collaboration with The Union }\end{array}$ & $\begin{array}{l}\text { - The ERS and The Union Joint Public Health } \\
\text { Fellowship in Respiratory Infections programme was } \\
\text { launched in } 2018 \text { as a pilot scheme } \\
\text { - The fellowship recipient is hosted by The Union }\end{array}$ & $\begin{array}{l}\text { Deadline: } 1 \text { December } 2019 \\
\text { Duration: } 12 \text { months }\end{array}$ & $\begin{array}{l}\text { Less than } 15 \% \\
\text { (based on first } \\
\text { pilot call only) }\end{array}$ \\
\hline
\end{tabular}

\#: estimation only, as the success rate depends on the number of applications received for each call. For the latest news and developments, please consult the ERS website: www.ersnet.org/professional-development/fellowships

knowledge back to the home centre/country. In light of the continuous rise in interest in this scheme, the number of fellowships available has increased, now allowing two calls per year. For all these fellowship programmes, special consideration is given to applicants from scientifically developing countries, which targets scientists and physicians from low income countries (as listed by the World Bank), along with residents of European countries with research gaps in the respiratory field. Similar special consideration is given to applicants from European countries with gaps in their research career path.

The RESPIRE Marie Skłodowska-Curie programme focuses on identifying the leaders of tomorrow in respiratory research and fosters investment in more basic and translational science. Following the RESPIRE3 (2016-2021) programme, a new RESPIRE4 programme has recently been selected for co-funding by the European Union, which will open in 2020. Successful applicants are assigned dedicated 
mentors who are recognised as experts by the ERS, to facilitate career development of the fellowship recipients, and to promote long-term interaction of the recipients with the Society. Both programmes build on the experience of the previous successful RESPIRE2 programme (2013-2018), which resulted in more than 120 publications, 160 presentations and 75 new collaborations, principally at the international level. RESPIRE4 will also pilot innovations such as the integration of patient representatives in the interview phase, in collaboration with the European Lung Foundation (ELF), as also highlighted in the ERS 10 principles for lung health [1].

In addition to the fellowship programmes outlined above, the ERS fellowships portfolio also contains a number of thematic programmes. The first of these, the Guideline Methodology Fellowship, offers training into methods and skills required to develop evidence-based clinical practice guidelines and is open to the entire ERS global membership. Recipients are subsequently encouraged to participate actively in ERS task forces.

The ERS fellowships portfolio has a dynamic profile and is constantly evolving in response to the changing needs of our society and membership. One recent change includes the discontinuation of the Fellowship in Industry. A second recent change is the latest addition to the portfolio: the ERS/The Union Joint Public Health Fellowship in Respiratory Infections; this was launched as a pilot in 2018 to build capacity in respiratory public health, epidemiology, and population-based research, and is jointly delivered with the International Union Against Tuberculosis and Lung Disease.

\section{Applying for an ERS fellowship: general requirements and tips/advice}

While there are no age limits, the current fellowships portfolio particularly targets ERS members in the earlier phases of their career. Candidates can choose from a wide range of opportunities, depending on their background and career goals, although some schemes may have a specific geographical or thematic focus. The minimum requirement for potential applicants is to hold an $\mathrm{MD}, \mathrm{MSc}, \mathrm{PhD}, \mathrm{MD} / \mathrm{PhD}$ (or equivalent), with the exception of the STRF, where applicants may still be engaged in their PhD studies. In the case of the RESPIRE fellowships, a $\mathrm{PhD}$ or 4 years of full-time research experience is required. Candidates are expected to develop their own research project and select their host centre/country within most of the fellowship programmes. Applications are submitted online via the dedicated ERS application platform introduced in 2017, which is accessible through the myERS portal.

For those interested in applying for an ERS fellowship, table 2 below provides useful advice and tips.

\section{Involving fellowship recipients and early career members in the evaluation process and in wider ERS activities}

The 2016-2019 fellowship strategy reinforced the involvement of former fellowship recipients, and the ERS Early Career Member Committee (ECMC), to support the ERS Fellowships and Awards Director with the evaluation of applications. Therefore, both the ERS Fellowships and Awards Working Group as well as the ERS College of Experts benefit from the active involvement and first-hand experience of former fellowship recipients and representatives of early career members, in collaboration with the ECMC. The evaluation process is driven by scientific excellence and is adapted to the nature of the specific scheme.

Moreover, ERS is deeply committed to involving ERS members in the earlier phases of their career in its wider portfolio. Fellowships can thus represent a unique gateway for recipients to get further involved in the Society's scientific and educational activities. At the ERS International Congress, as well as the Lung Science Conference, fellowship recipients have the opportunity to attend dedicated events (e.g. RESPIRE MeetUp, ECMC sessions), network and submit an abstract to present their projects. Several current and past fellowship recipients are equally engaged in scientific activities, such as ERS task forces and Clinical Research Collaborations, depending on their area of expertise.

\section{6-2019 period: key statistics}

Within the framework of the 2016-2019 fellowship strategy, across all ERS fellowship programmes, 157 fellowship recipients have been selected and received support to date. Of these, 32 LTRF as well as 16 RESPIRE3 Marie Skłodowska-Curie fellowship recipients were selected to pursue innovative research projects advancing science in a range of respiratory diseases. These diseases include airways disease, asthma, COPD, pulmonary hypertension, lung fibrosis, tuberculosis, lung cancer, sleep apnoea, paediatric lung and airway diseases (including cystic fibrosis), pulmonary rehabilitation, and epidemiology. In addition, 98 fellowship recipients were selected through the STRF or CTF programmes to learn a specific skill or technique, with a ripple effect in terms of transferring knowledge back to the home centre/country. Finally, 11 fellowship recipients were identified through specific programmes, such as the development of guidelines. As was the case in the past, there is an overall balance in terms of the gender of selected applicants. Just over $51 \%$ of 
TABLE 2 Top tips if you want to apply for an ERS fellowship programme

- Identify the most suitable ERS fellowship programme aligned with your research project and profile. Ensure that you meet all the eligibility requirements.

- Start early and familiarise yourself with the application guidelines as well as the online platform le.g. documents to collect, page limit). Contact fellowships@ersnet.org in case of any queries or doubts.

- Identify the best host centre/supervisor to fulfil your objectives. If you do not know where to start, ask your current supervisor or colleagues, look at publications in your field of interest, carry out Internet searches, attend relevant conferences or congresses and network. Keep in mind that the best host centre for a particular project may not necessarily be the most famous or largest host centre in the host country.

- Explain how you are addressing a need/gap within respiratory health and provide evidence le.g. using statistics, policy papers, recent literature). Highlight the potential benefits of your project (e.g. innovation, patient outcomes).

- Understand the scoring criteria for each programme and ensure that you address every single point in your application.

- Present your project in a clear, well-structured manner, making it easy for reviewers to follow. Get feedback from the proposed host supervisor but also other colleagues (e.g. statistician).

- Present a project that is feasible within the timeframe of the specific fellowship programme and do not forget to include contingency planning (e.g. potential risks, alternative ways forward).

- If requested, explain your methodology in detail, also covering power calculations and ethical considerations.

- Pay particular attention to the keywords and the order of the keywords that you provide. Your application will be assigned to a reviewer panel based on those keywords, taking the keywords in order of importance.

- If you have an interview, stick to the allocated presentation time and demonstrate that you "own" the project.

- Do not give up and re-apply integrating feedback received: in the past, several successful candidates were selected only after two or even three attempts.

Whilst these tips may be useful for all programmes, they are particularly relevant to Short- and Long-term Research Fellowships, Clinical Training Fellowships and RESPIRE applications.

fellowships awarded during 2016-2019 went to female researchers and clinicians. The spread of host countries for fellowship applications and fellowship awards is presented in figure 1.

Taking into account the 2013-2016 statistics presented in September 2016 in the European Respiratory Journal [2], some comparisons can be drawn with the former fellowships strategy (2013-2016). For instance, RESPIRE tends to be more focused on basic science due to the nature and duration of the programme while STRF and LTRF tend to cover more translational and/or clinical research; also reflecting the nature of applications. During 2016-2019, fellowship recipients from 43 nationalities were selected. This included 16 countries outside of Europe which accounted for more than $23 \%$ of selected candidates, as shown in table 3 . These trends are similar to the previous 2013-2016 period, with India and Australia having the highest number of non-European recipients, although the number of selected candidates from China has similarly increased since 2016. Within Europe, Italy remains the highest recipient of fellowships (12.1\%), as was also the case during the 2013-2016 period, while the number of fellowship recipients from the UK and Spain has grown over the past 3 years. These trends are generally reflected in the number of applications received from these three countries and more specifically relate to the STRF programme. The UK remains the most popular country in terms of hosting fellowship recipients (table 3 and figure 1), while the number of selected candidates going to the Netherlands and the USA has also grown over the past 3 years. These trends can be explained, to a great extent, by the number of STRF. More than $60 \%$ of all selected candidates under the STRF during the 2016-2019 period chose to undertake their fellowship in one of these three countries, to then return to their home country. The Global Fellowships, introduced under RESPIRE3, also enable to carry out research outside of Europe, before returning to a European host country.

\section{8 survey and external evaluation: general satisfaction across all programmes}

The results of a 2018 survey of past and ongoing fellowship recipients, as well as an external evaluation of RESPIRE, highlight general satisfaction with the fellowship programme, as well as positive impact on career development and the respiratory discipline as a whole. The great majority of all respondents agreed that the fellowship portfolio enhances career development opportunities, fosters networking and strengthens the respiratory specialty overall. $75 \%$ of all respondents continue to collaborate with the host centre following the end of the fellowship, while more than $80 \%$ stated that the fellowship helped to develop new collaborations. 

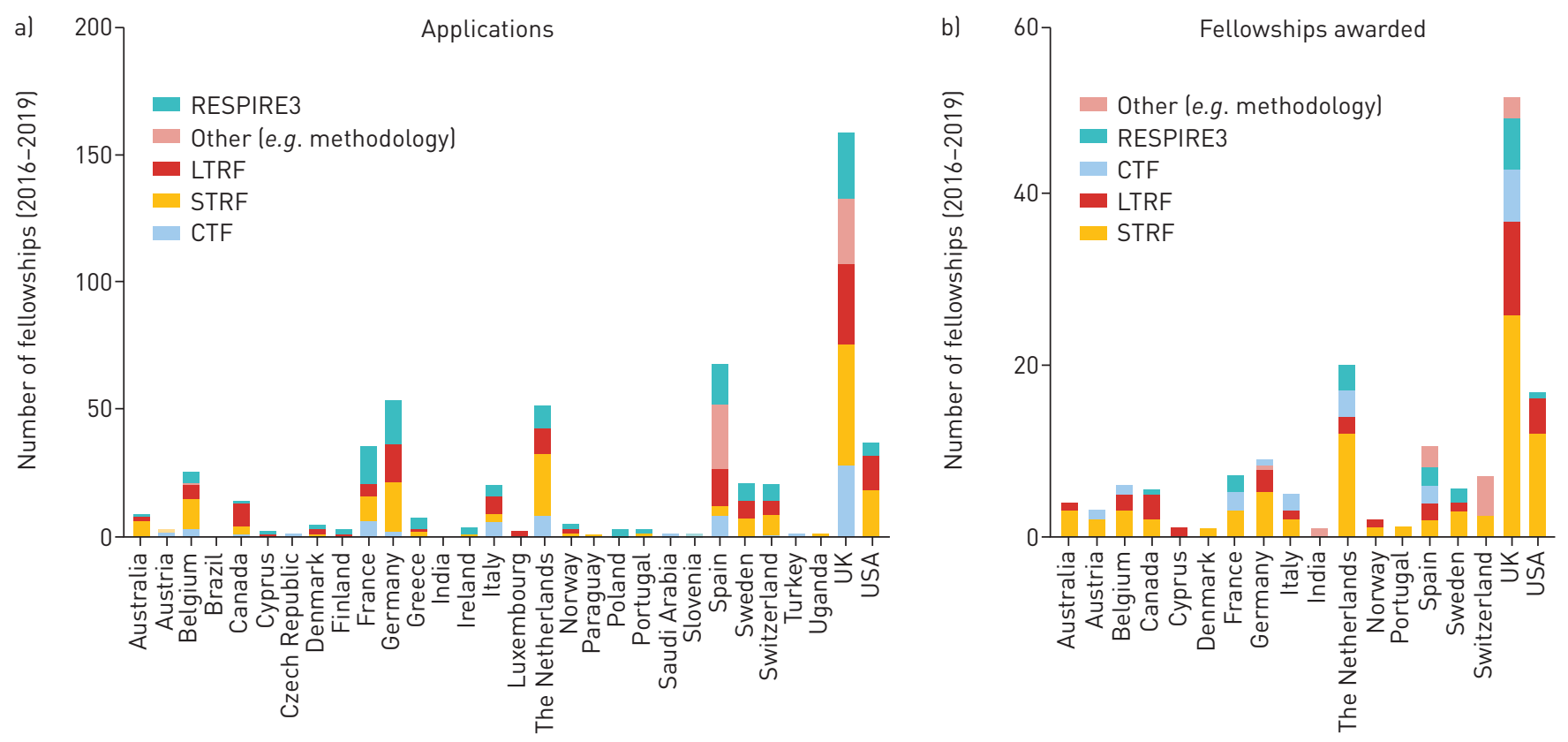

FIGURE 1 Fellowship applicants and awards, by country (2016-2019). a) The number of ERS fellowships applied for, and b) the number of fellowships awarded, by country, where the country represents the country of the host centre. In addition to the RESPIRE3 programme, data are also provided for the Long-term Research Fellowship (LTRF), Short-term Research Fellowship (STRF) and Clinical Training Fellowship (CTF) programmes. Due to the comparatively smaller number of fellowships in the Guidelines Methodology Fellowship, Fellowship in Public Health and Fellowship in Industry programmes, the data for those programmes have been collapsed into a single data set ("other").

Furthermore, as a result of the fellowship, survey respondents were involved in one or several ERS activities, in line with the Society's commitment towards involving ERS members in the early phases of their careers. This particularly related to the ERS International Congress (80\% of all respondents), the ERS College of Experts (45\%) and ERS scientific events (37\%) such as the Lung Science Conference and research seminars. According to the survey, former or ongoing fellowship recipients were also involved in an ERS committee, in educational/advocacy activities or in the development of ERS clinical practice guidelines, statements or technical standards.

\section{Conclusions}

The ERS fellowship portfolio offers a wide range of programmes and schemes to meet the needs of ERS members, particularly those in the earlier phases of their career. During the 2016-2019 period, the fellowship programmes were further developed and consolidated, to ensure that ERS members looking for a fellowship can identify the opportunity that is best suited to their background and career goals.

TABLE 3 ERS fellowship recipients (2016-2019 period) by nationality and host country

\section{Nationality of fellowship recipients (43 countries)}

\section{Italy (12.1\%)}

UK $(8.3 \%)$

Spain $(7.6 \%)$

The Netherlands (6.4\%)

France (5.1\%)

Germany and Greece ( $4.5 \%$ each)

Australia, India and Ireland (3.8\% each)

China, Denmark, Egypt and Poland (2.5\% each)

Belgium, Portugal, Turkey and Ukraine (1.9\% each)

Argentina, Belarus, Brazil, Canada, Croatia, Finland, Japan, Kenya,

Russian Federation and Sweden (1.3\% each)

Other 15 countries with $0.6 \%$ each

\section{Host country of fellowship recipients (18 countries)}

UK $(32.8 \%)$

The Netherlands (12.7\%)

USA $(10.8 \%)$

Spain $(6.7 \%)$

Germany (5.7\%)

France and Switzerland (4.5\% each)

Belgium (3.8\%)

Canada and Sweden (3.5\%)

Italy (3.2\%)

Australia $(2.5 \%)$

Austria (1.9\%)

Norway $(1.3 \%)$

Cyprus, Denmark, Portugal and India (0.6\% each) 
Over the past 3 years, 157 fellowship recipients were selected through competitive calls and received support in terms of training and skills development, with benefits throughout the whole spectrum of respiratory medicine and science. While the evaluation process for ERS fellowships continues to be driven by scientific criteria, the profile of successful fellowship recipients reflects the diversity and global dimension of ERS. Moreover, ERS fellowship programmes have not only enabled training for the next generation of respiratory researchers and clinicians, but provided benefits for the Society as a whole, in terms of enhanced involvement of selected candidates in its activities such as the ERS International Congress, as well as the Lung Science Conference, ERS task forces and ERS Clinical Research Collaborations. Therefore, through ERS fellowships, ERS builds a dedicated international respiratory scientific community fostering top-quality basic, translational and clinical research as well as evidence-based clinical practice in respiratory medicine.

Acknowledgements: ERS would like to thank all the organisations providing funding and support towards ERS Fellowship programmes. ERS would also like to thank the ERS Fellowships and Awards Working Group as well as ERS College of Experts for their invaluable involvement and contribution towards the evaluation and implementation of ERS fellowship programmes. ERS takes the opportunity to thank current staff members (in alphabetical order) at the ERS Executive Office who work on the coordination of ERS fellowship programmes: Valerija Arsovski, Amy Farr, Céline Genton, Albert Jimenez, Alessandra Marguerat, Rebecca Morgan, Carine Pannetier, David Rigau, Thomy Tonia, Maeve Tsu and Valérie Vaccaro.

Conflict of interest: R.E. Morty reports grants from European Union (EU), co-funding for joint ERS/EMBO fellowships from the European Molecular Biology Organization (EMBO), co-funding for joint ERS/TTS fellowships from the Turkish Thoracic Society (TTS), co-funding for joint ERS/ICS fellowships from the Indian Chest Society (ICS), co-funding for joint ERS/ALAT fellowships from Asociación Latinoamericana de Tórax (ALAT), co-funding for joint ERS/DZL fellowships from the German Center for Lung Research (Deutsches Zentrum für Lungenforschung; DZL), co-funding for joint ERS/SEPAR fellowships from Sociedad Española de Neumología y Cirugía Torácica (SEPAR), co-funding for joint ERS/SPLF fellowships from the Société de Pneumologie de Langue Française (SPLF), grants for funding and hosting ERS fellowship in industry from Novartis, training partnerships with National Institute for Health and Care Excellence (NICE UK) and Cochrane Iberoamerica - Spain, funding for joint fellowships from The Union Against TB and Lung Disease, co-funding for the joint Emiel F.M. Wouters fellowship from CIRO, during the conduct of the study; and is ERS Fellowships and Awards Director (2016-2019). L.E. Donnelly reports grants from European Union (EU), co-funding for joint ERS/EMBO fellowships from the European Molecular Biology Organization (EMBO), co-funding for joint ERS/TTS fellowships from the Turkish Thoracic Society (TTS), co-funding for joint ERS/ICS fellowships from the Indian Chest Society (ICS), co-funding for joint ERS/ALAT fellowships from Asociación Latinoamericana de Tórax (ALAT), co-funding for joint ERS/DZL fellowships from the German Center for Lung Research (Deutsches Zentrum für Lungenforschung; DZL), co-funding for joint ERS/SEPAR fellowships from Sociedad Española de Neumología y Cirugía Torácica (SEPAR), co-funding for joint ERS/SPLF fellowships from the Société de Pneumologie de Langue Française (SPLF), grants for funding and hosting ERS fellowship in industry from Novartis, training partnerships with National Institute for Health and Care Excellence (NICE UK) and Cochrane Iberoamerica Spain, funding for joint fellowships from The Union Against TB and Lung Disease, co-funding for the joint Emiel F.M. Wouters fellowship from CIRO, during the conduct of the study; grants from AstraZeneca and Boehringer Ingelheim, outside the submitted work; and is ERS Fellowships and Awards Director-Elect. D. Stolz reports grants from European Union (EU), co-funding for joint ERS/EMBO fellowships from the European Molecular Biology Organization (EMBO), co-funding for joint ERS/TTS fellowships from the Turkish Thoracic Society (TTS), co-funding for joint ERS/ICS fellowships from the Indian Chest Society (ICS), co-funding for joint ERS/ALAT fellowships from Asociación Latinoamericana de Tórax (ALAT), co-funding for joint ERS/DZL fellowships from the German Center for Lung Research (Deutsches Zentrum für Lungenforschung; DZL), co-funding for joint ERS/SEPAR fellowships from Sociedad Española de Neumología y Cirugía Torácica (SEPAR), co-funding for joint ERS/SPLF fellowships from the Société de Pneumologie de Langue Française (SPLF), grants for funding and hosting ERS fellowship in industry from Novartis, training partnerships with National Institute for Health and Care Excellence (NICE UK) and Cochrane Iberoamerica Spain, funding for joint fellowships from The Union Against TB and Lung Disease, co-funding for the joint Emiel F.M. Wouters fellowship from CIRO, during the conduct of the study; grants from AstraZeneca AG, Pan Gas AG, Weimann AG, Curetis AG, Boston Scientific AG, Circassia Pharmaceuticals and Lungenliga Switzerland, personal fees from AstraZeneca AG, Novartis AG, GSK AG, Roche AG, Zambon, Pfizer, Schwabe Pharma AG, Sanofi and Vifor AG, outside the submitted work; and is Education Council Chair ERS 2017-2020. N. Roche reports grants from European Union (EU), co-funding for joint ERS/EMBO fellowships from the European Molecular Biology Organization (EMBO), co-funding for joint ERS/TTS fellowships from the Turkish Thoracic Society (TTS), co-funding for joint ERS/ICS fellowships from the Indian Chest Society (ICS), co-funding for joint ERS/ALAT fellowships from Asociación Latinoamericana de Tórax (ALAT), co-funding for joint ERS/DZL fellowships from the German Center for Lung Research (Deutsches Zentrum für Lungenforschung; DZL), co-funding for joint ERS/SEPAR fellowships from Sociedad Española de Neumología y Cirugía Torácica (SEPAR), co-funding for joint ERS/SPLF fellowships from the Société de Pneumologie de Langue Française (SPLF), grants for funding and hosting ERS fellowship in industry from Novartis, training partnerships with National Institute for Health and Care Excellence (NICE UK) and Cochrane Iberoamerica Spain, funding for joint fellowships from The Union Against TB and Lung Disease, co-funding for the joint Emiel F.M. Wouters fellowship from CIRO, during the conduct of the study; and is ERS Guidelines Director (2018-2021). T. Welte reports grants from European Union (EU), co-funding for joint ERS/EMBO fellowships from the European Molecular Biology Organization (EMBO), co-funding for joint ERS/TTS fellowships from the Turkish Thoracic Society (TTS), co-funding for joint ERS/ICS fellowships from the Indian Chest Society (ICS), co-funding for joint ERS/ALAT fellowships from Asociación Latinoamericana de Tórax (ALAT), co-funding for joint ERS/DZL fellowships from the German Center for Lung Research (Deutsches Zentrum für Lungenforschung; DZL), co-funding for joint ERS/SEPAR fellowships from Sociedad Española de Neumología y Cirugía Torácica (SEPAR), co-funding for joint ERS/SPLF 
fellowships from the Société de Pneumologie de Langue Française (SPLF), grants for funding and hosting ERS fellowship in industry from Novartis, training partnerships with National Institute for Health and Care Excellence (NICE UK) and Cochrane Iberoamerica - Spain, funding for joint fellowships from The Union Against TB and Lung Disease, co-funding for the joint Emiel F.M. Wouters fellowship from CIRO, during the conduct of the study; and is ERS President (2018-2019). K.A. Forrest reports grants from European Union (EU), co-funding for joint ERS/EMBO fellowships from the European Molecular Biology Organization (EMBO), co-funding for joint ERS/TTS fellowships from the Turkish Thoracic Society (TTS), co-funding for joint ERS/ICS fellowships from the Indian Chest Society (ICS), co-funding for joint ERS/ALAT fellowships from Asociación Latinoamericana de Tórax (ALAT), co-funding for joint ERS/DZL fellowships from the German Center for Lung Research (Deutsches Zentrum für Lungenforschung; DZL), co-funding for joint ERS/SEPAR fellowships from Sociedad Española de Neumología y Cirugía Torácica (SEPAR), co-funding for joint ERS/SPLF fellowships from the Société de Pneumologie de Langue Française (SPLF), grants for funding and hosting ERS fellowship in industry from Novartis, training partnerships with National Institute for Health and Care Excellence (NICE UK) and Cochrane Iberoamerica - Spain, funding for joint fellowships from The Union Against TB and Lung Disease, co-funding for the joint Emiel F.M. Wouters fellowship from CIRO, during the conduct of the study; and is an employee of ERS. C.E. Brightling reports grants from European Union (EU), co-funding for joint ERS/EMBO fellowships from the European Molecular Biology Organization (EMBO), co-funding for joint ERS/TTS fellowships from the Turkish Thoracic Society (TTS), co-funding for joint ERS/ICS fellowships from the Indian Chest Society (ICS), co-funding for joint ERS/ALAT fellowships from Asociación Latinoamericana de Tórax (ALAT), co-funding for joint ERS/DZL fellowships from the German Center for Lung Research (Deutsches Zentrum für Lungenforschung; DZL), co-funding for joint ERS/SEPAR fellowships from Sociedad Española de Neumología y Cirugía Torácica (SEPAR), co-funding for joint ERS/SPLF fellowships from the Société de Pneumologie de Langue Française (SPLF), grants for funding and hosting ERS fellowship in industry from Novartis, training partnerships with National Institute for Health and Care Excellence (NICE UK) and Cochrane Iberoamerica - Spain, funding for joint fellowships from The Union Against TB and Lung Disease, co-funding for the joint Emiel F.M. Wouters fellowship from CIRO, during the conduct of the study; and is ERS CRC Director (2016-2019) and ERS Science Council Chair-Elect. G.G. Brusselle reports grants from European Union (EU), co-funding for joint ERS/EMBO fellowships from the European Molecular Biology Organization (EMBO), co-funding for joint ERS/TTS fellowships from the Turkish Thoracic Society (TTS), co-funding for joint ERS/ICS fellowships from the Indian Chest Society (ICS), co-funding for joint ERS/ALAT fellowships from Asociación Latinoamericana de Tórax (ALAT), co-funding for joint ERS/DZL fellowships from the German Center for Lung Research (Deutsches Zentrum für Lungenforschung; DZL), co-funding for joint ERS/SEPAR fellowships from Sociedad Española de Neumología y Cirugía Torácica (SEPAR), co-funding for joint ERS/SPLF fellowships from the Société de Pneumologie de Langue Française (SPLF), grants for funding and hosting ERS fellowship in industry from Novartis, training partnerships with National Institute for Health and Care Excellence (NICE UK) and Cochrane Iberoamerica - Spain, funding for joint fellowships from The Union Against TB and Lung Disease, co-funding for the joint Emiel F.M. Wouters fellowship from CIRO, during the conduct of the study; and is ERS Science Council Chair (2016-2019).

\section{References}

1 Horváth I, Barry M, Brusselle G, et al. The European Respiratory Society's 10 Principles for Lung Health. Eur Respir J 2018; 52: 1801373.

2 Belvisi MG, Morty RE, Rohde G, et al. The ever-expanding ERS fellowship programmes: achievements over the past 3 years. Eur Respir J 2016; 48: 595-599. 